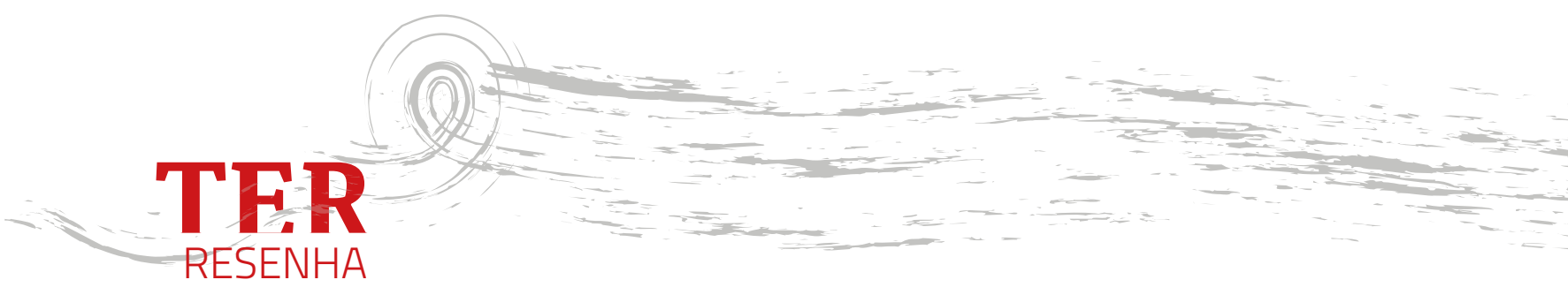

Universidade de São Paulo,

CAROLINA JUNQUEIRA DOS SANTOS

São Paulo, Brasil.

École des Hautes Études en Sciences Sociales, Paris, França.

\title{
AS IMAGENS E A POTÊNCIA DOS ENCONTROS
}

Andrea Barbosa et al. (org.). 2016. A experiência da imagem na etnografia. São Paulo: Terceiro Nome. 335 p.
Começo a leitura do livro por seus filmes - objetos visuais, tal como pensado por Catarina Alves Costa, resultantes de etnografias diversas. Ainda sem saber para onde caminhará a teoria, os filmes nos dão pistas, propõem desvios do puramente científico, nos inundam de imagens, sons, pessoas que dão visibilidade à relação estabelecida entre pesquisadores e pesquisados ao mesmo tempo que tornam essa separação uma mera nebulosidade, já que a ideia simplista e colonizadora de sujeito e objeto se dispersa, aqui, para dar lugar a encontros.

Tratam-se de encontros, o livro e os filmes. Encontros, via pesquisa, de pessoas, de inúmeras relações possíveis, de olhares múltiplos. 0 objeto fílmico-textual, dentro das bordas de um livro convencional portando também dois DVDs, divide-se em nove filmes e 14 artigos, além da apresentação dos organizadores e de prefácio e posfácio de autores convidados. Este livro é um dos resultados de três projetos temáticos financiados pela Fapesp ao longo de 18 anos e desenvolvido no Departamento de Antropologia da Universidade de São Paulo, mais especificamente no Grupo de Antropologia Visual (Gravi). Este grupo, desde seus primórdios em meados da década de 1990, vem pesquisando os mais diversos usos da imagem dentro de uma perspectiva antropológica, procurando novas linguagens e possibilidades visuais para a etnografia.

Dividido em três seções, o texto percorre os seguintes temas centrais: "Cinema e Antropologia"; "Fotografia e Etnografia"; "Experiências Transdisciplinares". Dos 14 artigos presentes, 10 foram escritos por pesquisadores 
do Gravi, metade deles em coautoria, o que foi desejado pelo próprio grupo para obter maior interação entre as reflexões. Os outros quatro artigos são de autores estudados pelo grupo e que serviram como material de referência e inspiração em suas pesquisas. Com o objetivo de "aliar ao texto uma nova poética experimental centrada na imagem" (Barbosa et al. 2016, 10), todos os artigos evocam o uso da imagem como uma ferramenta poderosa e transformadora no processo etnográfico. Tendo diante de si uma dupla dimensão de contato e contágio, a antropologia convoca, aqui, outras áreas do conhecimento - a fotografia, o cinema, o teatro, a música, as artes plásticas - para com elas estabelecer novos vínculos, mas vínculos que permanecem, essencialmente, moventes, instáveis.

Para adentrar seus textos e filmes, tomemos mais detalhadamente o livro em sua ordem dada, a começar pelas seções temáticas. A primeira delas, "Cinema e Antropologia", inicia-se com um pequeno texto de Trinh T. Minh-Ha, cineasta e escritora vietnamita aclamada por sua obra que renovou a ideia documental no cinema contemporâneo. Em "Olho mecânico, ouvido eletrônico, e a atração da autenticidade", a autora faz uma densa crítica à tradição dos filmes etnográficos construídos com a ideia de acessar uma naturalidade cinematográfica ou uma "neutralidade ideológica da imagem", "na busca por um uso científico do filme" (Ibid., 29). Abrir essa coletânea com esse artigo é já desmontar, de imediato, a imagem etnográfica como aquela pura, neutra, produzida por pesquisadores/cineastas/fotógrafos também neutros. Aqui, já logo sabemos: trata-se de estarem presentes, juntos, pesquisadores e pesquisados, tentando quebrar inclusive essas denominações, essas separações, em prol de uma imagem que fale do encontro.

O artigo seguinte "Etnoficção: uma ponte entre fronteiras", de Alexandrine Boudreault-Fournier, Rose Satiko Gitirana Hikiji e Sylvia Caiuby Novaes, aborda a produção do filme Fabrik Funk, presente na coletânea, ao mesmo tempo que evoca uma contundente reflexão sobre o fazer cinematográfico na antropologia, desorientando a noção de verdade em direção à ficção como elemento potencialmente constitutivo da imagem etnográfica. Levando adiante o eco das considerações de Trinh T. Minh-Ha, aqui não há sequer um rastro daquela suposta neutralidade/naturalidade científica da imagem. Estamos, por outro lado, nos terrenos arenosos da etnoficção. A voz de Jean Rouch ainda ressoa dizendo que "fazendo de conta ficamos mais perto da realidade" (Ibid., 43). As autoras, imersas na produção compartilhada do filme, relatam a experiência dos encontros, das colaborações, da criação coletiva, da improvisação, entre outros elementos que surgiram no decorrer do processo. No filme, os protagonistas, moradores de Cidade Tiradentes, o maior conjunto habitacional da América Latina, encenam seus próprios papéis, construindo uma trama sobre o funk e as configurações sociais que se estabelecem ao redor dele. 
Paul Henley, em seu artigo "Narrativas: a verdade velada do documentário etnográfico?", põe-se em diálogo com os textos anteriores ao evocar os modos de fazer e as estruturas narrativas dos filmes etnográficos. 0 texto soa como uma espécie de manifesto contra "um resíduo persistente de positivismo" (Ibid., 64) que faz o realizador pensar que a instauração de uma estrutura narrativa no filme etnográfico não seria, de fato, legítima. Mas Henley é preciso e enfático ao dizer que todos os filmes etnográficos são representações, e não espelhos voltados para o mundo, e é a partir dessa irrefutável constatação que ele pensará as narrativas, as tramas e as intervenções na cronologia do filme.

Nadja Marin e Paula Morgado, em "Filmes indígenas no Brasil: trajetória, narrativas e vicissitudes”, abordam a produção audiovisual indígena através da rememoração de sua trajetória, sua história, seus projetos e filmes. Desde as primeiras experiências com vídeo entre populações indígenas no Brasil, na década de 1980, passando pelo aclamado projeto "Vídeo nas Aldeias" e pelo programa televisivo Programa de Índio, até as primeiras indagações sobre a presença indígena no ciberespaço, as autoras discutem as perspectivas políticas do uso da imagem, a produção indígena da autoimagem, a transmissão de conhecimento. Aqui, aliás, o texto caminha para um ponto interessante e fundamental no pensamento sobre imagens etnográficas e seu poder de transmissão. Se antes, em diversos grupos, a transmissão somente se dava por via oral e gestual, agora o vídeo se transforma no grande arquivo mnemônico. Não sendo mais movente na performance, na permanente transformação corporal, a memória oferecida pelo vídeo, estática, traz aos grupos indígenas uma nova forma de transmissão de conhecimento, e será preciso entender como ambas formas memoriais se afetam e se transformam.

Bruna Triana e Diana Gómez, em "A análise fílmica na antropologia: tópicos para uma proposta teórico-metodológica”, tomam como referência para análise o filme Hunger, de Steve McQueen. Pensando o cinema como objeto e problema antropológico, as autoras evocam Walter Benjamin e suas reflexões sobre experiência, narração e mimesis para empreenderem a análise do filme dentro de uma "dupla perspectiva teórico-metodológica” (Ibid., 113). Passando por reflexões sobre espectador, montagem, afetos, corpos, as autoras buscam um diálogo no texto apesar da mencionada diferença de lugares que elas ocupam como espectadoras. Elas dirão que, entre ambas, "há certo descompasso de interesses e de formas de assistir ao filme" (Ibid., 116). Porém não fica clara, ao longo do texto, essa divergência das análises, o que poderia ter sido interessante para esboçar mais nitidamente as muitas formas de se experimentar a imagem.

No último artigo da seção, “O corpo no cinema”, David MacDougall se propõe a pensar os diversos corpos presentes na experiência cinematográfica. 
Os corpos postos em questão são o corpo do espectador, o corpo do cineasta, o corpo do próprio filme. A extensa e magnífica análise do autor nos faz pensar no cinema como algo que provoca o nosso encontro com aquilo que também somos nós, como se o filme fizesse emergir outros corpos de nós mesmos, enquanto esses corpos modificam permanentemente os corpos da imagem e, com isso, a própria imagem. Estamos todos - espectadores, cineastas, filmes - entremeados, misturados, perturbados uns pelos outros. "O filme pode ser uma ficção, mas os corpos não são" (Ibid., 133), dirá MacDougall, levando-nos em direção à dimensão de impregnação, experiência e transformação que o cinema produz.

Partimos, então, para a próxima seção, em que se discute o encontro entre "Fotografia e Etnografia". o texto "Rastreando a fotografia", de Elizabeth Edwards, propõe-se a pensar e rastrear a fotografia utilizada em contexto antropológico. A partir de três "instantâneos" - que tratam não de imagens específicas, mas de instantes históricos - e das categorias de evidência, poder e agência, Edwards explora as funções e os usos diversos da fotografia pela disciplina antropológica ao longo do tempo. 0 artigo, num certo tom evolutivo da prática fotográfica na antropologia, percorre as ideias de verdade fotográfica, cientificidade do aparato, poder, pose, exploração do corpo/da imagem do outro e as vertentes contemporâneas do uso da imagem fotográfica, como a reapropriação e o recomprometimento, que desejam "encontrar um presente para as fotografias históricas” (Ibid., 176), ou, ainda, os projetos colaborativos e comunitários em torno da produção e do uso da imagem. Apesar de todo o "rastreamento" empreendimento pela autora, ela deixa em aberto, no fim, o destino da fotografia dentro da prática antropológica, levando em consideração as transformações permanentes a que ambas estão sujeitas.

Andrea Barbosa, no artigo "Fotografia, narrativa e experiência", relata o processo de trabalho em um bairro de Guarulhos/SP, no qual realizou, durante quatro anos, diversas oficinas fotográficas com os moradores. A partir de uma abordagem dos usos e das funções da imagem, e de seu caráter agenciador de relações sociais, a autora investiga a fotografia tomando como eixo sua própria experiência etnográfica na comunidade, em que ela propôs aos moradores o exercício fotográfico de suas próprias experiências na vida do/no bairro. Para além do meramente visível na imagem, o que Barbosa pretende trazer para análise é a relação entre experiência e memória como uma das tantas e possíveis realidades da fotografia. A autora propõe ao leitor um olhar para as imagens produzidas, ou, mais especificamente, um espreitamento, o que ela imagina como movimento exploratório pelas imagens. 0 texto traz algumas fotografias e também esse gesto de olhá-las, analisá-las, adentrá-las, fazendo-nos notar a vida que habita a imagem, a vida que a excede. Ver o que a foto não mostra, "mergulhar em outras camadas, outras profundidades" 
(Ibid., 198). o filme Pimentas nos olhos, presente na coletânea, é também um dos resultados do trabalho de Andrea Barbosa realizado na região mencionada. Com efeitos visuais mais televisivos e uma trilha musical em evidência, o filme relata histórias da vida comum do bairro a partir de quatro vozes centrais.

Em "Alguns apontamentos sobre fotografia, magia e fetiche", Alice Villela e Vitor Grunvald desejam pensar a agência fotográfica a partir dos ecos de suas pesquisas pessoais, com campos etnográficos bastante diferentes. Notando que, apesar dessa distância, "uma estranha afinidade" se apresentava, Villela e Grunvald investigam as relações entre pessoas e fotografias. Entretanto, o artigo não se pretende como o empreendimento de uma comparação cultural, servindo, sobretudo, para trazer à luz questões fundamentais para o pensamento da agência das coisas. Passando por uma extensa e densa bibliografia, o artigo convoca inúmeros teóricos para fazer ressoar a relação entre fotografia, magia e fetiche.

No último artigo desta seção, a fotografia é pensada no trabalho etnográfico a partir de um outro viés. Aqui, o seu uso se dá, especialmente, como ferramenta de documentação/observação no campo. Ewelter Rocha, em "Objeto, imagem e percepção", analisa os altares domésticos das casas de devotos localizadas na Ladeira do Horto, em Juazeiro do Norte. 0 autor investiga as semelhanças estruturais de diversos altares para entender a lógica íntima que os habita e seu sentido sagrado. A partir também de uma reflexão sobre imagens, como a relação entre percepção e imaginação, o autor retoma a ideia de uma agência dos objetos expostos nos altares e nas relações afetivas estabelecidas com eles. As fotografias produzidas ao longo de sua pesquisa lhe possibilitam suspeitar de uma forma básica, uma ordem comum entre os altares fotografados, a que o investigador dá o nome de forma-altar, e que ele reconstitui digitalmente como uma forma padrão simplificada. o filme de Ewelter Beata, uma santa que não sorri, presente na coletânea, põe em cena o processo de confecção de imagens santas de beatas também em Juazeiro do Norte.

Chegamos à última seção de textos do livro com suas "Experiências transdisciplinares". Edgar Teodoro da Cunha, em "A intermitência das imagens: exercício para uma possível memória visual Bororo", discorre sobre sua pesquisa de campo, realizada desde o ano 2000 em aldeias indígenas Bororo, o que resultou em um filme etnográfico e alguns ensaios fotográficos. $\mathrm{O}$ autor convoca Aby Warburg, especialmente através de seu Atlas Mnemosyne, no qual junto com as vozes de Agamben e Didi-Huberman pensa as imagens como instâncias vivas, viventes, que se colocam em permanente relação umas com as outras, com o mundo, com as pessoas, (des)montadas, (re)montadas, (re)configuradas infinitamente. A partir de um material visual próprio produzido em campo e 
de imagens de arquivo de diferentes épocas sobre os Bororo, Cunha se propõe a investigar o uso e/ou o destino que se pode dar a esses materiais. Para o autor, levando em conta a pouca visibilidade do grupo em questão, torna-se ainda mais urgente a ideia de se pensar o uso das imagens produzidas e recolhidas.

Em "Montagem, teatro antropológico e imagem dialética", Carolina Abreu e Vitor Grunvald tomam de partida o conceito de montagem, técnica original do cinema, para irem em direção à experiência antropológica. Para isso, os autores mergulham em uma densa bibliografia antropológica, repleta de reflexões sobre o cinema etnográfico e a insurgência da ideia de presença autoconsciente do cineasta no seu fazer fílmico, o que abre brechas para aquilo que Rouch elaborou como "antropologia compartilhada" e MacDougall, como "cinema participativo". Nesses casos, o filme torna-se um lugar de encontro, de desencontros, de questões postas, abertas, partilhadas entre aquele que filma e aquele é que filmado, em interconexões que permitem o acesso de uns ao mundo dos outros. Convocando também Eisenstein, Vertov, Benjamin, Taussig, Didi-Huberman, Brecht, entre tantos, e permeado de dezenas de notas de rodapé, o texto é um mar absolutamente teórico de reflexões sobre imagem, montagem e experiência antropológica.

Francirosy Campos Barbosa, em seu texto "Somos afetados: experiências mágicas e imagéticas no campo religioso", além de trazer à luz uma perspectiva íntima e pessoal da pesquisa, que nos desloca bruscamente do denso artigo teórico anterior, evoca também o seu filme presente na coletânea, Allah, Oxalá na trilha Malê. No filme, a realizadora produz o encontro - físico e conceitual - do islamismo com o candomblé, traçando um percurso fascinante entre ambos centrado na figura Malê, nome dado aos muçulmanos negros que chegaram ao Brasil durante a escravidão. Tecnicamente, o filme possui alguns problemas, como uma visível sujeira na lente em determinados planos. Mas isso não é capaz de desfazer o encanto do filme e as relações que ele explicita. Sinto o mesmo encanto pelo artigo da pesquisadora, em que ela relata sua experiência no fazer etnográfico, também convocando a de outros pesquisadores. Na única fotografia presente no artigo, vemos Francirosy entre os dois interlocutores principais do filme, o corpo da realizadora implicado na imagem, tal como no texto. Escrito de forma intimista, o texto soa quase como uma carta, e, sendo também pesquisadora, emociono-me com o que reconheço daquilo que realmente nos afeta e transforma. Da mesma forma que o corpo da autora está implicado ali, via texto e imagem, o corpo do leitor também é convocado com todas suas experiências.

No último artigo do livro, "Etnografia e hipermídia: a cidade como hipertexto e as redes de relações nas ruas em Niterói/RJ”, Ana Lúcia Marques 
Camargo Ferraz nos apresenta a pesquisa empreendida junto com moradores de bairros populares de Niterói, através da qual ela se pergunta: "o que pode a etnografia na linguagem hipermídia?" (Ibid., 307). Tomando como eixo a ideia do "dar a ver", via rede, aquilo que está pelas ruas sob uma densa camada de invisibilidade, a investigadora procurou entender como a etnografia se torna possível em multimídia, uma etnografia que acompanhasse a metamorfose que é a própria cidade. Pensando na cidade também como hipertexto, "que contém retratos e paisagens, música e ruído, narrativas e performances em mosaico" (Ibid., 322), é interessante e instigante imaginar uma etnografia que fosse capaz de produzir em si outro hipertexto que falasse dessa cidade, ou melhor, falasse de uma das tantas cidades que habitam aquilo que chamamos de cidade. Na verdade, não haveria jamais uma cidade no singular - a própria experiência etnográfica em questão deixa isso claro. Existirão sempre tantas cidades quanto pontos de vista diferentes. É esse projeto denso e ambicioso, intitulado "Cartografias da Margem", que temos o prazer de conhecer no texto de Ferraz. Da mesma pesquisadora, temos o filme $O$ aprendiz do samba, no qual aborda outra experiência etnográfica. Aqui, jovens músicos apresentam velhos sambas em encontros musicais intergeracionais que comovem todos presentes.

Para além dos filmes já mencionados ao longo dessa resenha, outros estão também presentes na coletânea embora desvinculados dos artigos. Em Baile para matar saudades, Érica Giesbrecht evoca, junto com seus interlocutores - homens e mulheres negros entre setenta e noventa anos de idade -, os antigos bailes de gala na cidade de Campinas, frequentados, majoritariamente, pela comunidade negra. Esses senhores e senhoras são figuras centrais no movimento cultural negro da cidade hoje. A pesquisadora justapõe os antigos bailes de gala - que aparecem como forte lembrança entre os entrevistados - à cena musical atual da comunidade, essencialmente dedicada a repertórios afro-brasileiros. Recriando no final, com os entrevistados, um baile como os de antigamente, a realizadora faz a história se movimentar junto com o filme, no qual produz um espaço de experiência para as pessoas envolvidas.

Danzas para Mamacha Carmen, de Aristóteles Barcelos Neto, acompanha uma festa ritual no vilarejo de Paucartambo, no Peru. Essa festa, que acontece nos meses de julho, saúda Nossa Senhora do Carmo em quatro dias de danças com 19 grupos de pessoas fantasiadas e mascaradas. 0 filme acompanha um pouco de todos esses grupos e de suas danças, além de apresentar depoimentos de pessoas envolvidas na festa. Esse parece ser o filme mais bem realizado, técnica e conceitualmente, dessa coletânea, além de ser esteticamente sedutor, tanto pelas cores, danças e fantasias quanto por sentirmos o corpo que filma em meio a tudo, como se através dele pudéssemos projetar o nosso próprio corpo dentro da imagem em meio à dança. 
Vende-se pequi, de André Lopes e João Paulo Kayoli, uma produção inteiramente compartilhada entre realizadores indígenas e não indígenas, faz reverberar o texto de Marin e Morgado em que se discutiu a produção do filme etnográfico com os povos indígenas. Aqui, índios Manoki vendem pequi à beira da estrada e esse é o mote para que eles decidam investigar antigos mitos envolvendo o pequi. A partir de uma oficina de vídeo, os jovens saem em busca dos velhos, instigando-os a contar a história do pequi. Novamente temos questões relativas a encontros e conversas intergeracionais. 0 filme resultante é bonito, simples e instigante. Através do artifício daquilo que se quer contar - a história do pequi -, outras tantas camadas se revelam: as relações, gerações, memórias e o novo, aquilo que inevitavelmente se transforma.

Trans_versus 1, pequeno videorretrato de Vitor Grunvald, é um deleite. Esteticamente impecável e belo, o filme põe em cena Lizz Camargo, responsável por uma importante festa crossdresser na cidade de São Paulo. Deslocando o som da imagem, Grunvald produz um efeito audiovisual incrível em que acompanhamos o rosto de Lizz, seus gestos e toda a movimentação de pessoas no camarim em que ela é filmada, ao mesmo tempo em que sua voz em off nos relata histórias da festa e de sua concepção.

É muito nítido o espírito de interlocuções, partilhas, participações, diálogos e trânsitos entre artigos e filmes dessa coletânea. Fica clara a origem do material como advinda de um grupo de estudos. Tudo se cruza e se soma, o que faz da leitura e do olhar um belo exercício de perceber essas tantas conexões. 0 livro que temos em mãos trata, sobretudo, de encontros - voltamos à palavra essencial. Estar diante do outro é também estar diante de si visto pelo outro, e é nesse encontro que fará sentido toda etnografia. Essa coletânea de textos e filmes nos fala recorrentemente disso, pondo à prova palavra e imagem para dar visibilidade às potências do encontro com o outro e consigo mesmo. Fazendo ainda ecoar algumas palavras de Francirosy Campos Barbosa, em seu belo texto, imaginemos o encontro como aquilo que potencialmente borra os limites entre o eu e o outro.

Volto ao título do livro, A experiência da imagem na etnografia. Acho curioso notar a possibilidade textual de ser a própria imagem aquela que experiencia algo no trabalho etnográfico. o que seria a experiência da imagem? O modo como ela age, recebe, dá, comunica. Isso serve para lembrar que nós não manipulamos, simplesmente, os dispositivos fazedores de imagem. A imagem, ela mesma, age. Ela experimenta. Ela funciona ou não. Ela escolhe, mente. Ela deixa pistas, rastros. E nós, deste outro lado, construímos com elas, junto a elas, em seu canto mágico, nunca inocente, sempre em transformação. 


\section{CAROLINA JUNQUEIRA DOS SANTOS}

Doutora em Artes pela Universidade Federal de Minas Gerais (UFMG), com estágio na Université de Strasbourg. Desenvolveu uma vasta pesquisa sobre o universo das fotografias familiares memoriais e post-mortem, junto com diversos estudos sobre morte e representação do corpo desaparecido. É pós-doutoranda no Departamento de Antropologia da Universidade de São recebido Paulo (USP), e realiza atualmente um estágio de pesquisa na École des Hau14.07.2017 tes Études en Sciences Sociales, em Paris, com financiamento da Fapesp, aprovado desenvolvendo pesquisas sobre monumentos e memoriais aos mortos. É 17.01.2018 pesquisadora do Grupo de Antropologia Visual (Gravi) da USP. 